\title{
The Effect of Straw Addition on Properties of Slag Cement
}

\author{
Liguang $\mathrm{XIAO}^{1, \mathrm{a}}$, Jingyao $\mathrm{LI}^{1, \mathrm{~b}}$
}

${ }^{1}$ School of Materials Science and Engineering, Jilin Jianzhu university, Changchun 130118, China

axlg627@163.com, b13756946735@163.com

\begin{abstract}
Keywords: Straw; Slag; Geopolymer Cement; Straw-polymer composites material
Abstract. This paper mainly studied the influence of the amount of straw on the initial setting time and final setting time of the polymer cement, as well as the influence on the mechanical properties and thermal conductivity. Learning from the experiment, we could find that the porosity increased with the increase of straw and the strength of straw-polymer composites material gradually decreased. When the straw content reached to $7 \%$, its strength was still up to $13.7 \mathrm{MPa}$, at this time the thermal conductivity was $0.17 \mathrm{~W} / \mathrm{m} \cdot \mathrm{K}$. Compared with aerated concrete, under the same coefficient of thermal conductivity, its strength was 2 times of aerated concrete.
\end{abstract}

\section{Introduction}

China was a large agricultural country. The annual output of straw can reach to 700 million tons, which only 5\% could be effectively used. Most of the straw had been burned. It not only made the serious pollution of the environment, but also made a lot of waste of resources. Slag cement was a green cementitious material. Its outstanding feature was that the early strength was high and the hydration rate was fast. So it was easy to produce the phenomenon of condensation. But the straw contained many lignin, cellulose, sugar and other substances, which could play a retarder effectively. It could slow down the slag polymer cement hydration process. The thermal conductivity of straw was similar to asbestos, which could effectively play the role of insulation [1-4]. Therefore, the composite utilization of straw and slag cement was a worthy subject.

\section{Experimental process}

Raw Materials. Corn straw: 0.8-1 cm;II grade fly ash; Slag: Jilin Yatai; Water glass: modulus is 2.13; $\mathrm{NaOH}$ : analytical grade for industrial use; Cement clinker.

Experimental Apparatus. JR-KZ300DS-type cement mortar compressive and bending machine;CD-DR3030B thermal conductivity tester;TM3030 scanning electron microscope; DM-4L frequency conversion planetary ball mill; JJ-6 cement mortar mixer.

Saturated Water Absorption of Straw. The moisture absorption of straw: The straw sample was placed in the drying oven at 80 degrees for drying $5 \mathrm{~h}$, then the mass was weighed and recorded as $M_{0}$.After that, the dry straw was placed in distilled water to soak for 5 h.Then the water was filtered out with a sieve, until there was no water dropped.At this time, the quality of straw in the air was $\mathrm{M}_{1}$.The rate of water absorption was calculated as formula (1).The water absorption rate of straw was $130 \%$.

$\mathrm{E}=\left(\mathrm{M}_{1}-\mathrm{M}_{0}\right) / \mathrm{M}_{0}$

M0--- Mass of dry straw in air

$\mathrm{M}_{1---}$ Mass of saturated absorbent straw in air

Making the straw absorbed full of water according to the water absorption rate. A certain amount of straw was weighted and placed in $80^{\circ} \mathrm{C}$ drying box for $5 \mathrm{~h}$. While weighing $130 \%$ water sprayed evenly on the surface of straw, so that the straw can absorb water fully.

Production of Straw Pulp. The compressive and flexural specimens were divided into 8 groups, and the $\mathrm{NaOH}$ was accounts for $5 \%$ of the quality of cementitious materials. $\mathrm{NaOH}$ and water glass was mixed with the ratio of 3:7, while the slag and fly ash mixed in the proportion of 3:1.The amount of straw incorporation was $0 \%-7 \%$ of the cementitious materials. A constant amount of water was added based on the ratio 0.28 of water-to-cement, at the same time this materials were put into JJ-6 cement mortar mixer to stirred 2 minutes. The paste was filled in a mold with 
dimensions of $40 \times 40 \times 160 \mathrm{~mm}$ and vibrated it. After 24 hours of natural hydration, the molds were demolded. After that, the specimens were cured in a rapid curing box (curing temperature: $62^{\circ} \mathrm{C}$ ). The compressive strength was measured after 24 hours. First of all, using JR-KZ300DS type compression machine for bending test and it would be divided into two pieces for compressive strength test. The loading speed was $1 \mathrm{~mm} / \mathrm{min}$.

The thermal conductivity coefficient was divided into 8 groups, while the dosage of each component and the method was the same with the compression and the bending test. The paste was filled in a mold with dimensions of $300 \times 300 \times 30 \mathrm{~mm}$ and vibrated it. After disassembling the mold ,it was dried in the drying oven with $100^{\circ} \mathrm{C}$ for $5 \mathrm{~h}$. When it decreased to room temperature, the thickness of the four points was measured and the average value was taken. Then they were took into the thermal conductivity. The hot plate temperature was $55{ }^{\circ} \mathrm{C}$ and the cold plate temperature was $25^{\circ} \mathrm{C}$, the average thickness was $31 \mathrm{~mm}$. Table 1 showed the composition of the straw-slag polymer paste.

Table 1 Composition of polymer composites incorporating straw

\begin{tabular}{ccccccc}
\hline Materials & Fly ash & Slag & Sodium hydroxide & Water glass & Straw & Water \\
\hline Quality & 300 & 900 & 48 & 112 & $1 \%-7 \%$ & 340 \\
\hline
\end{tabular}

Determination of Initial Setting Time and Final Setting Time. The paste was immediately put into a circular mold and shocked several times, then the circular mold was placed into the curing box. Near the initial setting time, the test carried on every 5 minutes. It was the initial coagulation state when the test needle sunk to the bottom plate $4 \mathrm{~mm} \pm 1 \mathrm{~mm}$. When it was near the final setting time, the test carried on every 15 minutes, when the final setting test needle could not leave marks on the specimen, it achieved the final setting.

Determination of Open Porosity After 3 days of curing, the 8 tested pieces were completely soaked in water for a period of time. The quality of the test piece in water, the quality in the air and the quality after drying at 100 degrees for 10 hours were measured. The water absorption was calculated according to the formula (2).

$\mathrm{P}=\left(\mathrm{W}_{2}-\mathrm{W}_{3}\right) /\left(\mathrm{W}_{2}-\mathrm{W}_{1}\right)$

$\mathrm{W}_{1-----}$ The mass of the specimen in water

$\mathrm{W}_{2-----}$ The mass of the specimen in air

W3----- The mass of dried specimens

\section{Results Discussion and Analysis}

The Influence of Straw Content to the Setting Time of Slag Cement. The influence of straw content on the setting time of slag cement was shown in Table 2.

Table 2 Effect of the straw content on setting time of slag cement

\begin{tabular}{lcccccccc}
\hline \multicolumn{1}{c}{ Straw content $(\%)$} & 0 & 1 & 2 & 3 & 4 & 5 & 6 & 7 \\
\hline Initial setting time $(\min )$ & 18 & 25 & 31 & 36 & 40 & 45 & 57 & 72 \\
\hline Final setting time $(\min )$ & 38 & 96 & 132 & 280 & 341 & 459 & 619 & 863 \\
\hline
\end{tabular}

It could be seen from Table 2 that the initial setting time and the final setting time of the slag cement were obviously prolonged with the increase of the straw content. It showed that the incorporation of straw can provide sugars, wax and other substances, it could be adsorbed on the surface of cement mineral particles to form a adsorption layer. It had a strong inhibitory effect to the hydration of cement and hindered the hydration of cement. So the slag polymer cement hydration rate slowed down. Therefore, straw could be used as a retarder to effectively solve the problem of agglomeration of slag cement, and it could expand its application space in the construction field.

The Influence of Straw Content on the Porosity of Slag Cement. The effect of straw content on the porosity of slag cement was shown in Fig.1. It could be seen from Figure 1 that with the increase of straw content, the porosity of cement system increased gradually. The reason was that there were many hollow holes inside the straw and provided a certain porosity. While the interface between straw and cement paste also had many cracks, so that the porosity of the straw slag polymer cement system was further increased. 


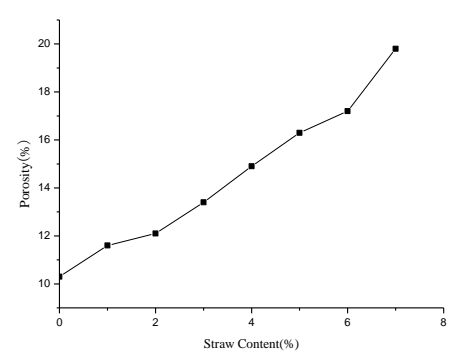

Fig.1.The relationship between the straw content and porosity.

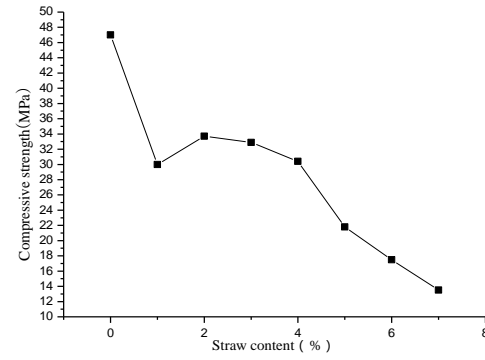

Fig.2.The relationship between the compressive strength and the amount of straw.

Effect of the Straw Content on Compressive Properties on Polymer Cement Paste. It could be seen from Fig. 2. The strength of the quick curing $24 \mathrm{~h}$ of the polymer cement paste decreased with the increase of the straw content, and the compressive strength of the cement paste was obviously lower than that of the pure poly. The strength of cement paste fluctuated less when the content of straw was $1 \%-4 \%$. Because slag cement itself had the characteristic of high early strength, so it was not obvious to the early hydration when a small amount of straw was mixed. When it was more than $4 \%$, the compressive strength decreased obviously, one of the reasons was the more straw incorporation, the more wax and sugar and other substances on surface and hindered the hydration of cement, thus the strength reduced. Another reason was that the incorporation of straw to the original combination of the cement material made many cracks. The straw could not be fully integrated with the polymer and the interface bonding was poor. There were many micro-cracks which resulted the decrease of strength. As shown in Figure 3.

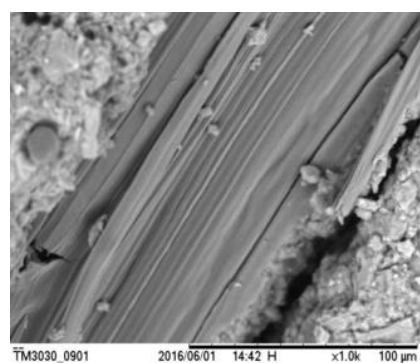

Fig.3.SEM of the interfacial bonding of straw. and polymer cement

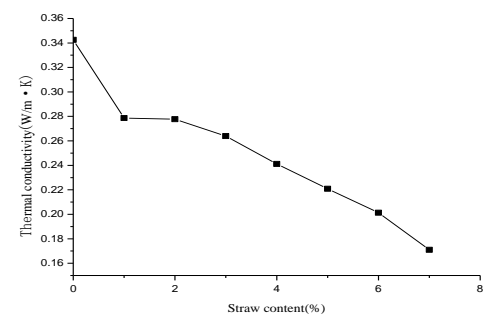

Fig.4. The relationship between Straw content and the thermal conductivity.

Effect of the Straw Content on Thermal Insulation Properties of Polymer Cement. Thermal conductivity trend was shown in Figure 4.It could be seen from the figure, when other factors were the same conditions, the thermal conductivity showed a decreasing trend with the increase of straw content. The smaller the thermal conductivity, the better insulation performance. The reason for the decrease of the thermal conductivity was that the porosity of the cement paste of the straw polymer increased with the addition of the straw content. As shown in Fig.1. At first the pore was filled with gas which flowed very weak and formed a bad conductor. The second, the addition of straw made the quality of cement composite materials more light, which was also one of the reasons leading to the reduction of thermal conductivity.

\section{Conclusions}

The influence of straw on the initial setting time and the final setting time of the slag cement was large. With the increase of the straw content, the initial and final setting time raised gradually. So when the dosage was 3\% -4\% and the final setting time was 4-6 hours, it was a more reasonable content.

With the increase of straw content, the compressive strength of composite cement decreased. When the straw content was $4 \%$, the compressive strength was $33.7 \mathrm{MPa}$. The straw content was $7 \%$, the strength of the composite could get to $13.7 \mathrm{MPa}$. When it was more than $10 \%$, the cement hydration speed was very slow, and even still could not be released even after 24 hours of natural 
curing.

With the increase of straw content, the thermal conductivity of the cement-based composites decreased significantly. When the content of straw was $7 \%$, the thermal conductivity was $0.17 \mathrm{~W} / \mathrm{m} \cdot \mathrm{K}$. Compared with aerated concrete, under the same coefficient of thermal conductivity, strength was 2 times of aerated concrete. Which indicated that the cement-based composites of straw polymer had excellent insulation property.

\section{Acknowledgement}

This work was financially supported by the Jilin province comprehensive utilization of straw technology innovation platform under special foundation(2014C-1).

\section{References}

[1].Van Deventer,Jannie S.J.,Provis,John L.,Duxson,Peter.Technical and commercial progress in the adoption of geopolymer cement[J].Minerals Engineering,2012,29: 89-104.

[2].Zhang Lin ,Liu Fusheng, Ren Shuxia,. Glazed hollow bead wheat straw composite insulation mortar with orthogonal test of ratio [J].Concrete, 2013,10: 139-156.

[3].Liu Hongfeng, $\mathrm{Yu}$ Zhenhuang. Straw fiber properties [J]. Journal of Donghua University.2002,4(28)2:123-128.

[4].Zhang Haiyan, Qi Shuliang, Cao Liang. Comparison of the mechanical properties of the cement mortar, mortar and concrete after high temperature [J]. Journal of Disaster Prevention and Mitigation Engineering.2015,01(35):11-16. 